\title{
Durability of Modified Fiber Concrete for Rigid Pavements
}

\author{
Andriy Mishutin \\ Odessa State Academy of Civil Engineering \& Architecture \\ Kos Zeljko \\ University North \\ Grynyova Iryna \\ Odessa State Academy of Civil Engineering \& Architecture \\ Lucia Chintea \\ Odessa State Academy of Civil Engineering \& Architecture
}

\section{Abstract}

Modified concretes and fiber concretes for rigid pavements have been investigated. Fourfactor experiment was conducted. The amount of Portland cement, polypropylene fiber, metakaolin and polycarboxylate superplasticizer varied in the experiment. All mixtures had the same mobility S2.

The active mineral additive metakaolin increases the compressive strength of concrete and its tensile strength in bending. The amount of metakaolin at the level of $15.20 \mathrm{~kg} / \mathrm{m}^{3}$ is rational. Due to a decrease in $\mathrm{W} / \mathrm{C}$ with an increase in the amount of superplasticizer Coral ExpertSuid- 5 to $0.9 .1 \%$, the compressive strength of concrete increases by $5.7 \mathrm{MPa}$, the tensile strength in bending increases by 0.5.0.6 MPa. Due to the introduction of polypropylene fiber, the tensile strength of concrete in bending increases by 0.6.0.9 $\mathrm{MPa}$, the frost resistance of concrete increases by 50 cycles. Due to the use of a rational amount of superplasticizer and metakaolin, the frost resistance of concretes and fiber concretes concrete increases by 50-100 cycles. The use of a rational amount of modifiers and fiber reduces the abrasion of concretes by $40.45 \%$.

The developed modified fiber concretes of rigid pavements, depending on the amount of Portland cement, have compressive strength from $55 \mathrm{MPa}$ to $70 \mathrm{MPa}$, tensile strength in bending from $8 \mathrm{MPa}$ to $9.5 \mathrm{MPa}$, frost resistance from F350 to F450, abrasion from 0.30 to $0.40 \mathrm{~g} / \mathrm{cm}^{2}$. Such strength, frost resistance and abrasion resistance allow the use of fiber concretes in pavements with the greatest load and ensures high durability of the material and corresponds to the directions and tasks of the state scientific and technical program "National Transport Strategy of Ukraine for the period up to 2030"

Keywords: pavement, concrete, strength, durability, modifiers, fiber. 
Paper type: Research article

Received: 6.1.2021.

Accepted: 21.2.2021.

DOI: $10.2478 /$ crdj-2021-0006

\section{Introduction}

Cement concrete pavements are the most effective for increasing the bearing capacity, performance and durability of highways. These characteristics of the material are important due to the increase in traffic intensity, the level of dynamic loads and axle loads of heavy vehicles. In modern conditions, axle loads often exceed $115 \mathrm{kN}$. Cement-concrete pavements better distribute pressure to the substrate than asphalt-concrete pavements, since their modulus of elasticity is greater than that of asphalt-concrete. Cement concrete pavement is resistant to the formation of seclusion and waves. These properties reduce vehicle fuel consumption and help to protect the environment from pollution. The quality of work of rigid pavements is less dependent on the effect of high temperatures in the hot season (Vozny, 2017).

The durability of rigid pavements is determined not only by their strength, but also by frost resistance and abrasion of concrete. It is possible to obtain an economical material simultaneously with high durability and strength of concrete for rigid pavements only with the use of effective modifiers (Chen at al., 2018). In the modern construction industry, polycarboxylate superplasticizers are most widely used as modifiers (Neville, 2000). The molecular structure of polycarboxylates makes it possible to accelerate the hydration of cement, and the rapid adsorption of molecules on cement particles and the dispersion effect provide an increase in the surface of the hydration reactions (Liu at al., 2019).

For concrete of rigid pavements, an effective method of increasing durability is the use of active mineral additives of the pozzolanic type (Gupta et al., 2008; Kroviakov et al., 2019), including metakaolin (Busari et al., 2019; Salimi et al., 2020). Metakaolin affects the process of structure formation of the cement matrix in concrete, reduces the permeability and shrinkage of concrete, and also increases its frost resistance and corrosion resistance (Gupta et al., 2008; Busari et al., 2019; Salimi et al., 2020). However, metakaolin has a high dispersion and has a positive effect on the durability and shrinkage of concrete only at a low W/C mixture, that is, when using a mineral additive together with a superplasticizer (Salimi et al., 2020).

Also, an effective method of increasing the strength, crack resistance and abrasion resistance of concrete for rigid pavements is the use of fiber (Gupta et al., 2008; Shen et al., 2012). Improvement of concrete properties when using fiber is explained by its ability to perceive tensile stresses and reduce shrinkage and swelling deformations (Choi et al., 2011).

Thus, there is an actual task of developing fiber concrete modified with polycarboxylate superplasticizer and metakaolin for rigid pavements. Such concretes are able to provide the necessary strength and durability of the pavements. 


\section{Methodology}

Investigation of properties of concrete for rigid pavements were conducted for the optimal 4-factorial (Jeff Wu et al., 2009). Such composition factors varied (Mishutin et al., 2020):

- $X_{1}$, amount of Portland cement (CEM II/A-S 42.5), from 400 to $500 \mathrm{~kg} / \mathrm{m}^{3}$;

- $\mathrm{X}_{2}$, the amount of polypropylene fiber (length $12 \mathrm{~mm}$, diameter $20 \mu \mathrm{m}$ ), from 0 to 2 $\mathrm{kg} / \mathrm{m}^{3}$;

- $X_{3}$, the amount of metakaolin (firing product of enriched kaolin clays), from 0 to 30 $\mathrm{kg} / \mathrm{m}^{3}$;

- $\mathrm{X}_{4}$, the amount of polycarboxylate superplasticizer Coral ExpertSuid-5, from 0.6 to $1 \%$ by weight of cement.

Crushed stone of fraction $5-10 \mathrm{~mm}$ and quartz sand with a modulus of 2.7 were used as aggregates for fiber concretes.

The mobility of mixtures of all studied concretes and fiber concretes was equal (S2). This mobility provides the convenience of paving a mixture for rigid pavements. Respectively, W/C of mixture depended on the concrete's composition.

The compositions of the investigated concrete and fiber-reinforced concrete of road surfaces are shown in Table 1.

Table 1

Compositions of the investigated concretes and fiber concretes of pavements $\left(\mathrm{kg} / \mathrm{m}^{3}\right)$

\begin{tabular}{lccccccc}
\hline No & cement & $\begin{array}{c}\text { crushed } \\
\text { stone }\end{array}$ & sand & metakaolin & fiber & $\begin{array}{c}\text { Super } \\
\text { plasticizer }\end{array}$ & water \\
\hline $\mathbf{1}$ & 450 & 1115 & 655 & 15 & 1 & 3,6 & 183 \\
\hline $\mathbf{2}$ & 400 & 1130 & 668 & 30 & 0 & 2,4 & 191 \\
\hline $\mathbf{3}$ & 400 & 1135 & 692 & 0 & 2 & 4 & 193 \\
\hline $\mathbf{4}$ & 500 & 1105 & 635 & 0 & 0 & 5 & 168 \\
\hline $\mathbf{5}$ & 500 & 1100 & 603 & 30 & 2 & 5 & 181 \\
\hline $\mathbf{6}$ & 500 & 1105 & 621 & 0 & 2 & 3 & 192 \\
\hline $\mathbf{7}$ & 450 & 1115 & 617 & 30 & 2 & 2,7 & 206 \\
\hline $\mathbf{8}$ & 450 & 1115 & 684 & 0 & 0 & 2,7 & 161 \\
\hline $\mathbf{9}$ & 450 & 1115 & 651 & 30 & 0 & 4,5 & 164 \\
\hline $\mathbf{1 0}$ & 500 & 1105 & 574 & 30 & 1 & 3 & 203 \\
\hline $\mathbf{1 1}$ & 400 & 1130 & 691 & 0 & 1 & 2,4 & 192 \\
\hline $\mathbf{1 2}$ & 400 & 1130 & 672 & 30 & 1 & 4 & 182 \\
\hline $\mathbf{1 3}$ & 500 & 1105 & 601 & 15 & 0 & 3 & 199 \\
\hline $\mathbf{1 4}$ & 400 & 1130 & 676 & 15 & 2 & 2,4 & 199 \\
\hline $\mathbf{1 5}$ & 400 & 1135 & 702 & 15 & 0 & 4 & 158 \\
\hline $\mathbf{1 6}$ & 500 & 1105 & 590 & 30 & 0 & 4 & 183 \\
\hline $\mathbf{1 7}$ & 400 & 1130 & 662 & 30 & 2 & 3,2 & 189 \\
\hline
\end{tabular}




\begin{tabular}{llllllll}
\hline 18 & 400 & 1135 & 710 & 0 & 0 & 3,2 & 163 \\
\hline
\end{tabular}

Properties of concrete were analyzed by experimental-statistical models.

\section{Results}

The W/C mixture varied depending on the composition of the concrete. Compressive strength, tensile strength in bending, frost resistance and abrasion were determined for all concretes (Table 2).

\section{Table 2}

W/C of mixture, compressive strength, tensile strength in bending, frost resistance and abrasion of the studied concretes and fiber concretes

\begin{tabular}{|c|c|c|c|c|c|}
\hline № & $W / C$ & $\begin{array}{c}\text { compressive } \\
\text { strength (MPa) }\end{array}$ & $\begin{array}{l}\text { tensile strength in } \\
\text { bending (MPa) }\end{array}$ & $\begin{array}{c}\text { frost } \\
\text { resistance }\end{array}$ & $\begin{array}{c}\text { abrasion } \\
\left(\mathrm{g} / \mathrm{sm}^{2}\right)\end{array}$ \\
\hline 1 & 0,406 & 59,4 & 8,32 & 400 & 0,35 \\
\hline 2 & 0,471 & 49,3 & 6,97 & 250 & 0,53 \\
\hline 3 & 0,474 & 45,2 & 7,21 & 300 & 0,41 \\
\hline 4 & 0,336 & 66,1 & 8,72 & 350 & 0,47 \\
\hline 5 & 0,361 & 65,0 & 9,22 & 450 & 0,29 \\
\hline 6 & 0,384 & 54,4 & 8,73 & 400 & 0,36 \\
\hline 7 & 0,455 & 51,1 & 8,49 & 300 & 0,36 \\
\hline 8 & 0,358 & 54,8 & 7,91 & 300 & 0,50 \\
\hline 9 & 0,364 & 65,4 & 8,22 & 350 & 0,45 \\
\hline 10 & 0,406 & 55,5 & 8,47 & 400 & 0,39 \\
\hline 11 & 0,478 & 41,8 & 7,35 & 250 & 0,45 \\
\hline 12 & 0,455 & 49,1 & 7,46 & 300 & 0,41 \\
\hline 13 & 0,398 & 56,6 & 8,07 & 350 & 0,46 \\
\hline 14 & 0,484 & 46,3 & 7,78 & 300 & 0,44 \\
\hline 15 & 0,396 & 60,9 & 7,61 & 300 & 0,49 \\
\hline 16 & 0,366 & 65,2 & 8,24 & 400 & 0,43 \\
\hline 17 & 0,469 & 51,1 & 7,62 & 300 & 0,42 \\
\hline 18 & 0,408 & 49,4 & 7,07 & 250 & 0,48 \\
\hline
\end{tabular}

\section{Discussion}

It was found that with an increase in the amount of Portland cement $\mathrm{W} / \mathrm{C}$ is projected to decrease. The use of polypropylene fiber necessitates an increase in W/C to maintain the mobility of the mixture. When using metakaolin due to its additional water consumption, $\mathrm{W} / \mathrm{C}$ mixture also increases. Increasing the amount of superplasticizer in the concrete composition from $0.6 \%$ to $0.9-1 \%$ significantly reduces the $\mathrm{W} / \mathrm{C}$ of the mixture. 
Also it was found that the amount of polypropylene fiber has a negligible effect on the compressive strength of the studied concretes and fiber concretes. Accordingly, Fig. 1 shows a diagram constructed on base of experimental-statistical model, which reflects the effect of the amount of Portland cement, metakaolin and superplasticizer on the compressive strength of fiber concretes.

The analysis of the diagram in Fig. 1 shows that when increasing amount of cement in the composition, the strength of concrete and fiber concrete is expected to increase. Metakaolin as an active mineral additive increases the strength of concrete. Rational for the strength of concrete is the amount of metakaolin from 15 to $20 \mathrm{~kg} / \mathrm{m}^{3}$. When increasing the amount of superplasticizer to $0.9 . .1 \%$, the strength of concrete and fiber concrete increases by 5.7 MPa. The positive effect of the additive is more noticeable for concretes with metakaolin. Concretes and fiber concretes with a rational amount of modifiers depending on the amount of Portland cement in the composition have a compressive strength from $55 \mathrm{MPa}$ to $70 \mathrm{MPa}$, which corresponds to classes C35/40C40/50.

For rigid pavements, important quality indicators are not only their compressive strength, but also tensile strength in bending. This is due to the multidirectional loads that the pavement receives during operation.

Figure 1

The effect of the amount of Portland cement, metakaolin and superplasticizer on the compressive strength of fiber concretes

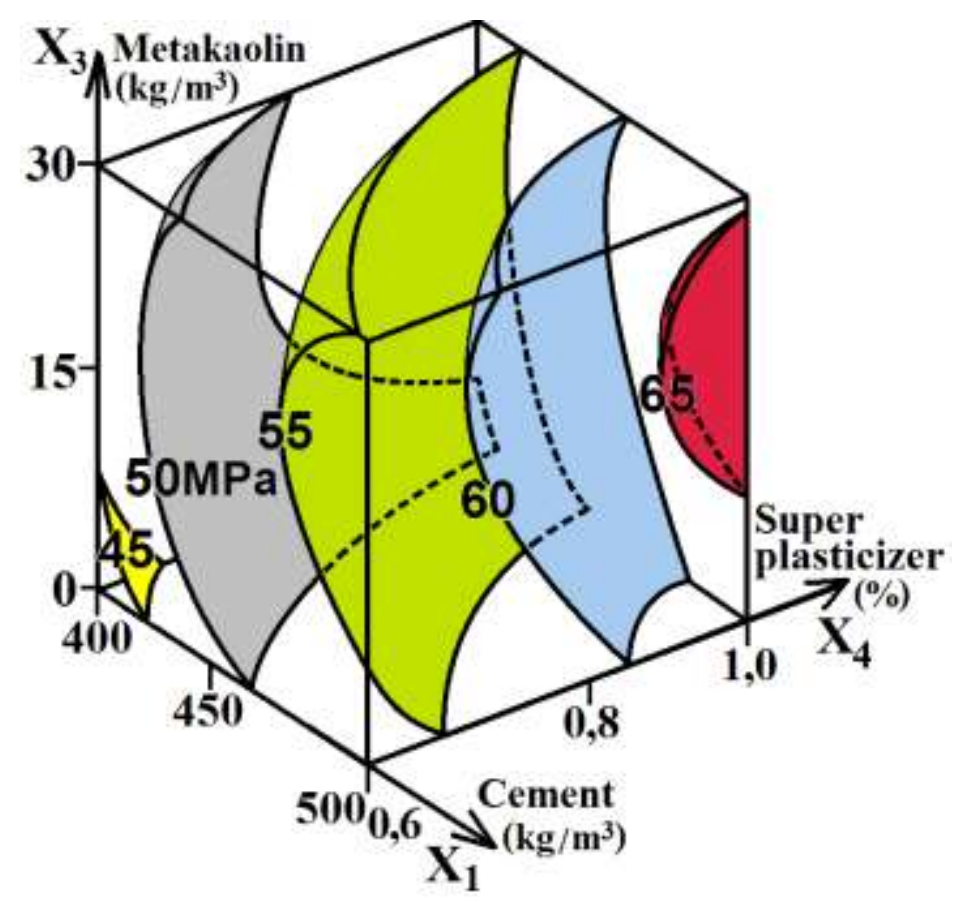

Source: Author's illustration 
The analysis shows that the tensile strength in bending of concrete and fiber concrete is significantly affected by the amount of Portland cement and the amount of polypropylene fiber. Due to the use of fiber tensile strength increases by 0.6..0.9 MPa. Thus, disperse reinforcement is an effective method of increasing the stability of cement concrete pavements under tensile loads. The tensile strength in bending of fiber concretes increases by $0.6 .0 .7 \mathrm{MPa}$ due to the use of a rational amount of modifiers. Overall, modified fiber concrete, depending on the amount of cement in their composition has tensile strength in bending from 8 to $9.5 \mathrm{MPa}$. Such strength provides high bearing capacity of concretes in rigid pavements of highways.

Frost resistance is an important condition for ensuring the durability of riding pavements. Concretes of pavements in the course of operation are exposed to repeated influences of freezing and thawing. The number of cycles of freezing and thawing of coatings can be much greater than the number of air temperature transitions through $0^{\circ} \mathrm{C}$. Experimentalstatistical model, which describes the effect of variable compositional factors $\left(\mathrm{x}_{1}-\mathrm{x}_{4}\right)$ on frost resistance of the studied concretes and fiber concretes, has the form:

$$
\begin{aligned}
& \mathrm{F} \text { (cycles) }=393+60 \mathrm{x}_{1} \pm 0 \mathrm{x}_{1}^{2}+8 \mathrm{x}_{1} \mathrm{x}_{2} \pm 0 \mathrm{x}_{1} \mathrm{x}_{3} \pm 0 \mathrm{x}_{1} \mathrm{x}_{4} \\
& +23 x_{2}-14 x_{2}^{2}-10 x_{2} x_{3} \pm 0 x_{2} x_{4} \\
& +7 x_{3}-29 x_{3}^{2}+7 x_{3} x_{4} \\
& +19 x_{4}-23 x_{4}^{2}
\end{aligned}
$$

According to the model (2) diagrams such as "squares on squares" were built and shown in Fig.2. When building the diagram, the square in the $x_{3}-x_{4}$ coordinates (the amount of metakaolin and the superplasticizer Coral ExpertSuid-5) was chosen as the bearing square. In the field of the bearing square 9 constructed squares reflect the effect of the amount of Portland cement and polypropylene fiber on the frost resistance of concrete and fiber concrete with the appropriate amount of modifiers.

The analysis of the diagram shows that the frost resistance of the studied concretes and fiber concretes is significantly affected by the amount of Portland cement and the amount of polypropylene fiber. Concretes with a Portland cement amount of $500 \mathrm{~kg} / \mathrm{m}^{3}$ have a frost resistance approximately 100 cycles higher than concretes with a binder amount of $400 \mathrm{~kg} / \mathrm{m}^{3}$. Frost resistance of concretes of rigid pavements increases by 50 cycles and more with use of fiber in the amount of $1,5-2 \mathrm{~kg} / \mathrm{m}^{3}$. Due to the use of a rational amount of modifiers $\left(0.8-1 \%\right.$ of superplasticizer and $15-20 \mathrm{~kg} / \mathrm{m}^{3}$ of metakaolin) frost resistance of concretes and fiber concretes increases by 50-100 cycles depending on the level of other compositional factors. In general, the developed modified fiber concretes of hard pavements depending on the amount of Portland cement in the composition have frost resistance from F350 to F450, which ensures their sufficient durability.

As noted above, the abrasion (abrasion resistance) of concrete is an important characteristic that largely determines the durability of road rigid pavements. Experimentalstatistical model, which describes the effect of variable compositional factors on abrasion of concretes and fiber concretes, has the form:

$$
\begin{aligned}
& \mathrm{G}\left(\mathrm{g} / \mathrm{sm}^{2}\right)=0,350-0,036 \mathrm{x}_{1} \pm 0,020 \mathrm{x}_{1}^{2}-0,016 \mathrm{x}_{1} \mathrm{x}_{2}-0,008 \mathrm{x}_{1} \mathrm{x}_{3} \pm 0 \mathrm{x}_{1} \mathrm{x}_{4} \\
& -0,056 x_{2}+0,030 x_{2}^{2} \quad \pm 0 x_{2} x_{3} \quad \pm 0 x_{2} x_{4} \\
& -0,006 x_{3}+0,012 x_{3}^{2} \quad \pm 0 x_{3} x_{4}
\end{aligned}
$$




$$
-0,018 x_{4}+0,022 x_{4}^{2}(2)
$$

The analysis of the model has shown that the amount of fiber and Portland cement most significantly affects the abrasion of the investigated concretes of rigid pavements, and the amount of metakaolin does not significantly affect. Accordingly, Fig. 3 shows a diagram constructed on base of experimental-statistical model (2), which reflects the effect of the amount of Portland cement, fiber and superplasticizer on the abrasion of concretes and fiber concretes.

Analysis of the diagram (Figure 3 ) shows that dispersed fiber reinforcement significantly reduces the abrasion of concrete of rigid pavements, that is, increases their abrasion resistance. Due to the using of polypropylene fiber in the amount of $1.5 . .2 \mathrm{~kg} / \mathrm{m}^{3}$, the abrasion of concrete is reduced by $0.11 . .0 .16 \mathrm{~g} / \mathrm{cm}^{2}$ (22..35\%). With an increase in the amount of cement from 400 to $500 \mathrm{~kg} / \mathrm{m}^{3}$, the abrasion of concrete and fiber-reinforced concrete decreases by $0.07-0.10 \mathrm{~g} / \mathrm{cm}^{2}$. This is due to an increase in the strength of concrete with an increase in the amount of Portland cement. By increasing the amount of superplasticizer, the W/C of the mixture decreases, respectively, the strength of concrete increases and abrasion decreases. The combined use of fiber and a rational amount of superplasticizer reduces the abrasion of concrete by $40-45 \%$. 
Figure 2

The effect of the amount of Portland cement, fiber, metakaolin and superplasticizer on the frost resistance of concretes and fiber concretes

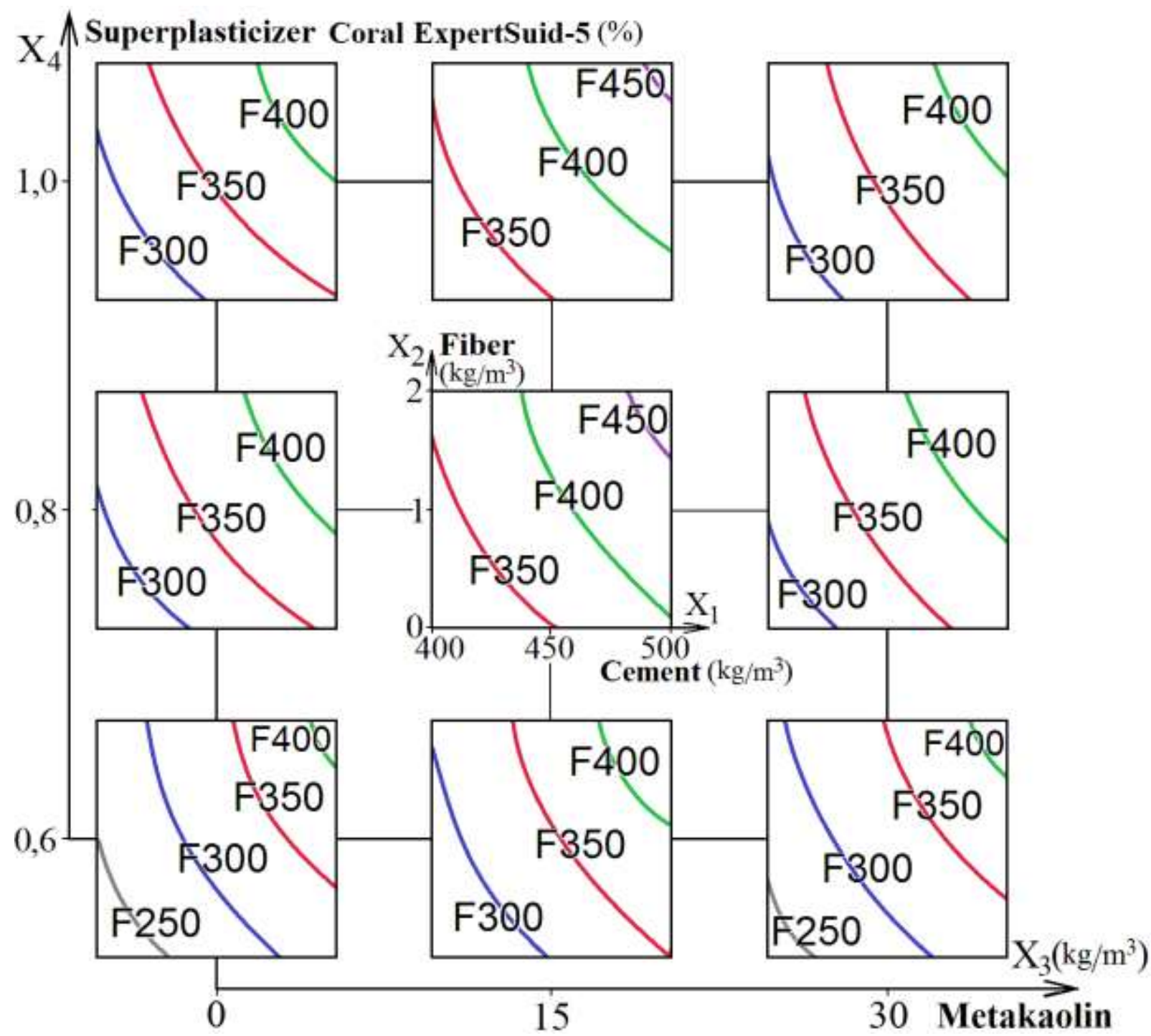

Source: Author's illustration 
Figure 3

The effect of the amount of Portland cement, fiber and superplasticizer on the abrasion of concretes and fiber concretes

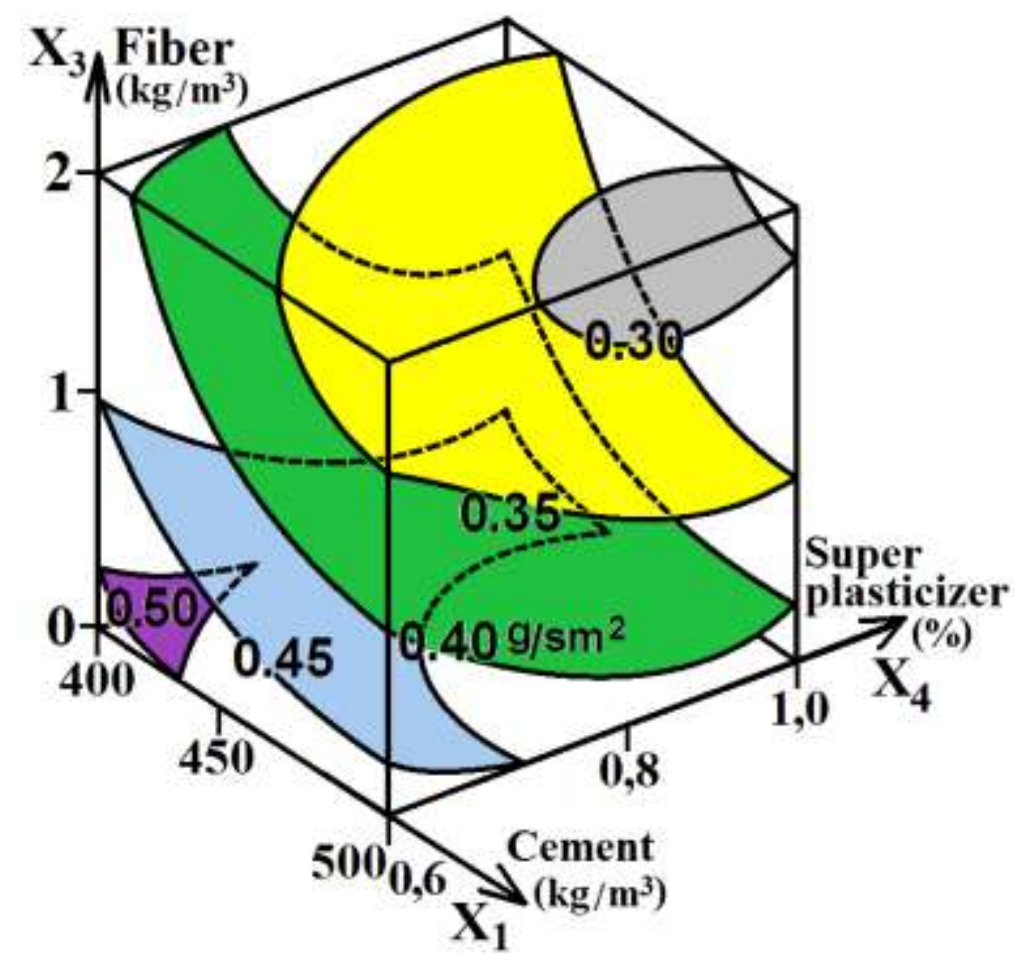

Source: Author's illustration

\section{Conclusion}

Cement-concrete coatings are the most effective for increasing the bearing capacity, characteristics and durability of highways. These characteristics of the material are important in connection with the increase in traffic intensity, the level of dynamic loads and axle loads of heavy vehicles. In modern conditions, axial loads often exceed $115 \mathrm{kN}$. Cement-concrete pavements better distribute pressure to the base than asphalt concrete pavements, since their modulus of elasticity are higher than that of asphalt concrete. The durability of rigid coatings is determined not only by their strength, but also by the frost resistance and abrasion of concrete. It is possible to obtain an economical material simultaneously with high strength of concrete for rigid pavements only with the use of effective modifiers. Modified concretes and fiber-reinforced concretes for rigid pavements have been investigated. A four-factor experiment was carried out. The amount of Portland cement, polypropylene fiber, metakaolin and polycarboxylate superplasticizer was varied in the experiment. All mixtures had the same S2 mobility. The mobility of the mixtures of all investigated concretes and fiber-reinforced concretes was the same (S2). This mobility makes it easy to laying mix for rigid pavements. Accordingly, the W/C of mixture depended on the composition of the concrete. For rigid pavements, important quality indicators are not only their compressive strength, but also their flexural tensile strength. 
This is due to the multidirectional loads that the road pavements experiences during operation. Frost resistance is an important condition for ensuring the durability of road pavements. Pavement concrete during operation is exposed to repeated effects of freezing and thawing. The number of freeze and thaw cycles for coatings can be much greater than the number of times the air temperature goes through $0{ }^{\circ} \mathrm{C}$. The frost resistance of the concretes and fiber-reinforced concrete under study are significantly influenced by the amount of Portland cement and the amount of polypropylene fiber. Abrasion (abrasion resistance) of concrete is an important characteristic that largely determines the durability of rigid road pavements. Thus, a rational amount of modifiers for concretes of rigid pavements was identified: polycarboxylate superplasticizer $0.9-1 \%$ and metakaolin $15-20 \mathrm{~kg} / \mathrm{m}^{3}$. Due to the dispersed reinforcement with polypropylene fiber, the use of a rational amount of metakaolin and polycarboxylate superplasticizer Coral ExpertSuid-5 were obtained: fiber concrete rigid pavements with compressive strength up to $70 \mathrm{MPa}$, tensile strength in bending up to $9.5 \mathrm{MPa}$, frost resistance up to $\mathrm{F} 450$ and abrasion less than $0.35 \mathrm{~g} / \mathrm{sm}^{2}$. High strength, frost resistance and abrasion resistance of modified fiber concretes allow their use in pavements with the highest load and ensure the durability of the material. Further research will analyze and develop modified fiberreinforced concrete, as well as carry out industrial tests in Ukraine and Moldova.

\section{References}

Vozny, S.P. (2017). Prospects for the development of cement concrete roads in Ukraine. Modern technologies and methods of calculations in construction, 6, 47-55.

Chen, Y., Cen, GP., Cui, YH. (2018). Comparative study on the effect of synthetic fiber on the preparation and durability of airport pavement concrete. Construction and Building Materials, 184, 34-44.

Neville, A.M. (2000). Properties of Concrete (4th ed.), Longman.

Liu, J., Yu, C., Ran, Q., Yang, Y. (2019). Recent advance of chemical admixtures in concrete. Cement and Concrete Research, 124, 105834.

Gupta, S., Rao, V.V.L.K., Sengupta, J. (2008). Evaluation of polyester fiber reinforced concrete for use in cement concrete pavement works. Road materials and pavement design, 9 (3), 441-461.

Kroviakov, S., Zavoloka, M., Dudnik, L., Kryzhanovskyi, V. (2019). Comparison of strength and durability of concretes made with sulfate-resistant portland cement and portland cement with pozzolana additive. Electronic Journal of the faculty of civil engineering Osijek - e-GFOS, 19, 81-86.

Busari, A., Akinmusuru, J., Dahunsi, B. (2019). Mechanical properties of dehydroxylated kaolinitic clay in self-compacting concrete for pavement construction. Silicon, 11 (5), 24292437.

Salimi, J., Ramezanianpour, A.M., Moradi, M.J. (2020). Studying the effect of low reactivity metakaolin on free and restrained shrinkage of high performance concrete. Journal of Building Engineering, 28, 101053. 
Shen, H.R., She, Y.X., Gao, P.W. (2012). The influence of polypropylene fiber on the performance of concrete pavement. Applied Mechanics and Materials, 178-181, 1099-1103.

Choi, S.Y. Park, J.S. Jung, W.T. (2011) A study on the shrinkage control of fiber reinforced concrete pavement. Procedia Engineering, 14, 2815-2822.

Jeff Wu, C. F., Hamada, M.S. (2009). Experiments: Planning, Analysis, and Optimization (2d ed.), Wiley \& Sons.

Mishutin A.V., Chintea L. (2020). The effect of modified additives on strength and frost resistance in fibrous concrete of rigid road pavements. Bulletin of Odessa state academy of civil engineering and architecture, 80, 64-74.

\section{About the authors}

Andriy Mishutin, Doctor of Technical Sciences, Professor, a head of the department of Highways and Airfields, Odessa State Academy of Civil Engineering \& Architecture. Area of scientific interest: hydraulic concretes, concrete for pavements, modifiers for concrete, increasing the durability of concretes. Member of the editorial boards of leading Ukrainian scientific publications. The author can be contacted at mishutin52@ukr.net

Kos Zeljko, PhD, Associate professor at the department of Civil Engineering, University North. Area of scientific interest: building materials, finite element method, load-bearing capacity, damaged reinforced concrete column, mathematical analysis, geotechnics and particularly energy efficiency. Owner of mandates on the base of state: Energy efficiency certifier, Occupational safety expert, Coordinator of occupational safety in civil engineering, Forensic expert in the field of civil engineering, Real estate assessment. He is actively engaged in number of EU funded projects and continuously participating in workshops and training related to edutation and research. The author can be contacted atzeljko.kos@unin.hr.

Grynyova Iryna, PhD in Technical Sciences, Assistant of the department of Reinforced Concrete Structures and Transport Facilities, Odesa State Academy of Civil Engineering \& Architecture. Area of scientific interest: finite element method, load-bearing capacity. The author can be contacted at Irene.grinyova@gmail.com

Lucia Chintea, graduate student of the department of Highways and Airfields, Odessa State Academy of Civil Engineering \& Architecture. Area of scientific interest: concrete for pavements, modifiers for concrete, increasing the durability of concretes. The author can be contacted at chintea.lucia@gmail.com 